\title{
Comparative genome mapping of sugar cane with other species within the Andropogoneae tribe
}

\author{
L. GRIVET* , A. D'HONT, P. DUFOUR, P. HAMON, D. ROQUES $\dagger$ \& \\ J. C. GLASZMANN \\ Centre de Coopération Internationale en Recherche Agronomique pour le Développement (C.I.R.A.D.), BP 5035, 34032 \\ Montpellier Cedex, France and $\dagger$ Centre de Coopération Internationale en Recherche Agronomique pour le \\ Développement (C.I.R.A.D.), Station de la Bretagne, 97487 Saint Denis Cedex, Réunion
}

\begin{abstract}
Comparative mapping within the tribe Andropogoneae has recently progressed with the development of mapped maize genomic probes that can be used for sorghum and sugar cane genomes. In the present study, data from previous reports were used to locate various linkage groups of sugar cane and sorghum on the genomic map of maize. Syntenic genome regions in the three plants were determined according to existing bridge-loci. The distribution of these synteny clusters closely matched the duplication pattern in maize. In several cases, the two arms of a single maize chromosome corresponded to at least two synteny clusters. There seem to be common chromosome rearrangements between maize and sugar cane and between maize and sorghum. In this respect, sugar cane and sorghum appear to be more closely related than either one with maize. A more detailed analysis of two synteny clusters was undertaken using recent sugar cane data to compare gene orders and recombination rates of the three plants. The three genomes showed colinearity in these regions. Distances between genes were similar in maize and sorghum, whereas sugar cane tended to display less recombination, at least in the varietal progeny investigated.
\end{abstract}

Keywords: genome mapping, maize, RFLP, sorghum, sugar cane, synteny.

\section{Introduction}

Sugar cane is the main sugar-producing crop. It is a member of the tribe Andropogoneae like maize and sorghum, two important cereal crops which have received much attention from molecular geneticists. Sugar cane belongs to the genus Saccharum, which appears to include only highly polyploid species. Modern varieties are mainly derived from interspecific hybridization between the sugar producing species, $S$. officinarum, and the wild species, $S$. spontaneum. These selected varieties are aneuploids with chromosome numbers typically in the 100-125 range with about 5-10 per cent contributed by the wild-type.

Molecular genetic markers cannot be applied to sugar cane as they are to most other plants owing to the high ploidy level of this crop. Linkage between two loci can only be determined with, for both loci, a 'single dose restriction fragment' (SDRF), i.e. a fragment corresponding to an allele present only once per

\footnotetext{
*Correspondence.
}

genome, which would therefore segregate as a monogenic marker (Wu et al., 1992). Such markers were found sufficiently often in progeny of a $S$. spontaneum clone to build a first molecular map for the Saccharum genus (Al-Janabi et al., 1993; Da Silva et al., 1993). In sugar cane varieties, many SDRFs would be markers from the $S$. spontaneum genome fraction because of the strong molecular differentiation between $S$. spontaneum and $S$. officinarum, and the greater allelic diversity occurring at each locus in $S$. spontaneum compared to $S$. officinarum (Glaszmann et al., 1989; Eksomtramage et al., 1992; Lu et al., in press). Segregation of this fraction has thus been monitored in a self progeny of a modern variety (D'Hont et al., 1994).

Comparative mapping using a diploid relative can help define the complex polyploid nature of species such as sugar cane. D'Hont et al. (1994) used maize DNA probes and revealed a large degree of synteny between markers mapping in maize and sugar cane, although a much lower recombination rate was observed in sugar cane. Nevertheless, gene orders of the two species could not be compared due to the small 
population of the progeny studied and the almost complete absence of recombination between the linked markers.

Similarly, comparative mapping of the sorghum genome using maize probes (Hulbert et al., 1990; Binelli et al., 1992; Whitkus et al., 1992; Melake Berhan et al., 1993) revealed a large degree of synteny, but there were several instances of chromosomal rearrangements.

In this paper, we generally compare the three crops by pooling information obtained from various published studies. We also obtain a more accurate comparison for specific regions of the genome by using a larger population of self progeny from a sugar cane variety, which permit investigation of gene order and map distances in this species.

\section{Materials and methods}

\section{Comparison of sugar cane, maize and sorghum maps on the basis of published data}

Our earlier study comparing sugar cane and maize linkage groups and two studies comparing sorghum and maize genomic maps (Whitkus et al., 1992; Melake Berhan et al., 1993) involved a number of common maize probes.

In the present study, we attempted a three-way comparison based on information obtained from these studies. The aim was to identify putative syntenic regions between the three species, that we termed 'synteny clusters' (SC). Putative SCs were first identified on the basis of 'bridge-loci' shared between linkage groups in sugar cane and sorghum (Fig. 1). We selected cases in which bridge-loci linked in sugar cane were also linked in sorghum, or belonged to two linkage groups sharing at least one common probe as determined in the two sorghum studies. The loci belonging to the respective linkage groups in the two plants were thus tentatively considered to be members of a single SC. We then studied the distribution of these SCs along maize chromosomes.

\section{Recombination within two specific linkage groups}

Plant materials The segregation analysis was performed on 81 individuals of the selfed progeny from the commercial sugar cane variety $\mathrm{R} 570$, created by the Centre d'Essai, de Recherche et de Formation, Réunion.

RFLP protocols Total DNA was extracted from freeze-dried leaf tissues according to the protocol of Saghai-Maroof et al. (1984) modified by Hoisington
(1992). DNA was digested with three restriction enzymes, namely DraI, HindIII and SstI, all known to yield easily readable profiles in sugar cane ( $\mathrm{Lu}$ et al., in press). The restriction fragments were separated by electrophoresis on 0.8 per cent agarose gels in TAE buffer. DNA was transferred onto nylon membranes (Hybond $\mathrm{N}+$, Amersham). Probes were labelled with $32 \mathrm{P}-\alpha \mathrm{dCTP}$ using the Amersham Megaprime commercial kit. Prehybridization, hybridization and washes were performed according to the protocols of Hoisington (1992). The prehybridization buffer contained $5 \times$ SSC, 0.2 per cent SDS, $1 \times$ Denhardt's, $0.1 \mathrm{mg} / \mathrm{mL}$ of sheared salmon sperm DNA. The hybridization buffer was supplemented with 10 per cent dextran sulphate. Blots were washed rapidly in $2 \times \mathrm{SSC}, 0.5$ per cent SDS at room temperature and then four times for $30 \mathrm{~min}$ in $0.1 \times \mathrm{SSC}, 0.1$ per cent SDS at $65^{\circ} \mathrm{C}$.

Probes The probes used were derived from maize genomic DNA libraries. The BNL probes were kindly supplied by $\mathrm{Dr}$ B. Burr of Brookhaven National Laboratory (Burr \& Burr, 1991) and the UMC probes by $\mathrm{Dr}$ Coe of the University of Missouri-Colombia (Coe et al., 1988; Gardiner et al., 1993). Eleven probes were selected from these sets. Seven of them mapped the two maize putative paralogous chromosomal segments 7L (BNL4.24, BNL8.39, BNL8.44, BNL15.21 and BNL16.06) and 2L (UMC4 and UMC137) that corresponded to the sugar cane linkage group D in the study of D'Hont et al. (1994). The four remaining probes mapped the maize chromosome arm 9S (BNL5.04, UMC81, UMC109 and UMC113).

Data analysis Hybridization patterns of all probes contained both monomorphic and polymorphic (present in some individuals and absent in others) bands. The SDRFs, i.e. the polymorphic bands whose segregation was compatible with a $3: 1$ ratio (chisquared test at the 1 per cent level), were retained for further analysis. When two SDRFs generated by the same probe (with the same or with two different restriction enzymes) displayed the same segregation pattern, the one with the fewer missing data (if any) was retained. The segregation analysis of SDRFs was performed using the MAPMAKER v2.0 software package (Lander et al., 1987) for the Macintosh. The multipoint analyses were performed using a minimum LOD score of three. Genetic distances were estimated with the Haldane mapping function. This first step led to identification of cosegregation groups. A composite map for each linkage group was then constructed by pooling the data of all the constitutive cosegregation groups and treating them as a whole progeny population as already described by D'Hont et al. (1994). This 


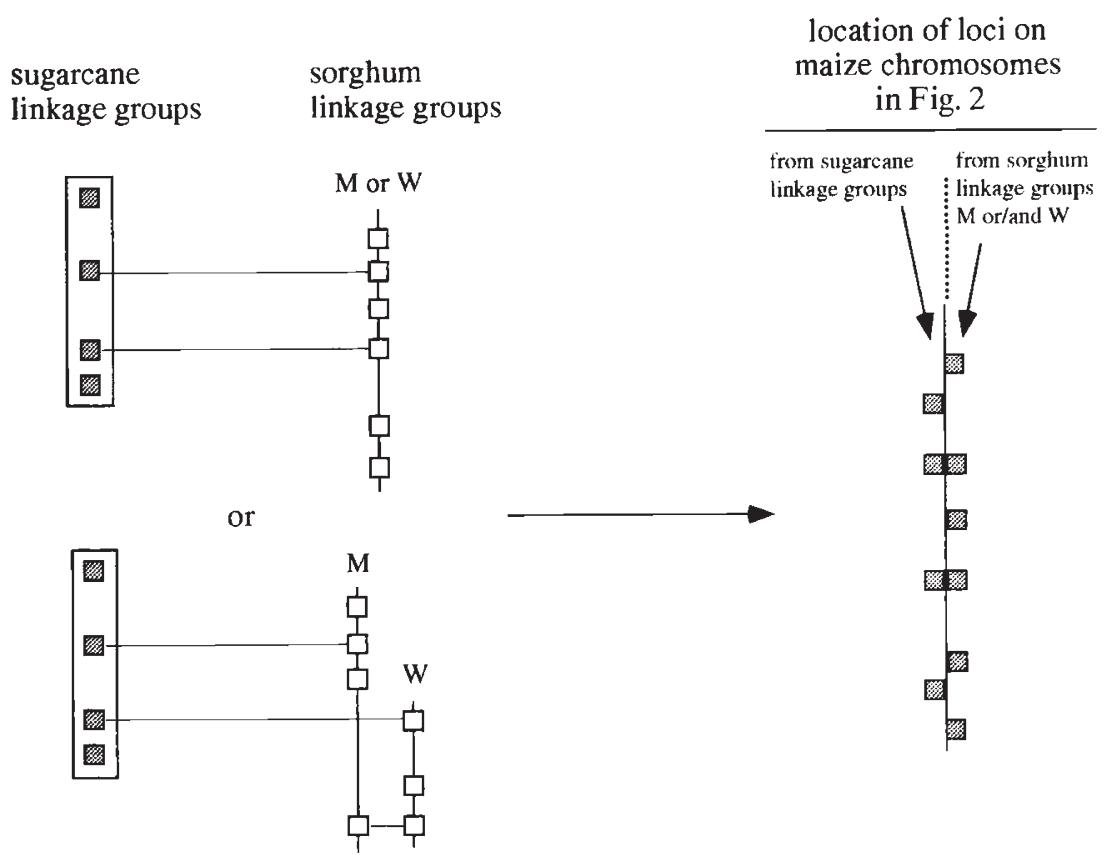

Fig. 1 Principles for constructing putative synteny clusters between sugar cane and sorghum on the basis of bridge-loci (see text). The squares symbolise RFLP loci revealed by maize probes and involved in sugar cane or sorghum (W for Whitkus et al., 1992; M for Melake Berhan et al., 1993) linkage groups. Horizontal lines indicate bridge-loci. The distribution of the synteny clusters along maize chromosomes is shown in Fig. 2. was undertaken to determine the gene order and to estimate the average map distances.

\section{Results}

\section{Tentative synteny clusters and their distribution along maize chromosomes}

Thirty-seven probes were involved in sugar cane linkage groups (34 from the study of D'Hont et al. (1994), plus UMC109, UMC113 and BNL05.04 from the present study). Among these, 20 had also been mapped in sorghum (Whitkus et al., 1992; Melake Berhan et al., 1993) and allowed determination of possible homoeology relationships (Table 1). One hundred and nineteen probes/isozyme loci belonging to putative sorghum and sugar cane SCs were thus located on the maize genome map for comparison (Fig. 2). The principles mentioned earlier and applied for drawing up Table 1 led to tentative grouping into seven synteny clusters (SCs), named after the corresponding sugar cane linkage groups.

The overall pattern (Fig. 2) calls for the following remarks.

(1) Most of the tentative SCs included many loci belonging to the same maize linkage group. However, many tentative SCs had loci which mapped onto two different maize chromosomes. In both crops this applied to maize chromosomes 1 and 9,1 and 5,2 and 7,2 and 10, 3 and 8,6 and 9 and to a lesser extent 4 and 5. The ambivalent localization of these SCs agrees with the duplicated clusters of genes described by Helentjaris et al. (1988) and Dowty \& Helentjaris (1992) in the maize genome. The tentative SCs thus seemed to be valid in maize, but several versions coexist in this plant due to the extent of duplication.

(2) The distribution indicated a number of cases in which a single maize chromosome could correspond to at least two distinct SCs. This was the case for chromosomes 1, 2, 5 and 9, for which these distinct SCs seem to span distinct chromosome arms, suggesting that there are large chromosome rearrangements in the maize genome as compared to those of sorghum and sugarcane. Several facts support this inference:

- in the two studies on sorghum (Whitkus et al., 1992; Melake Berhan et al., 1993), selected probes were used to obtain continuous genomic coverage of the maize map; hence there is little chance that gaps occur in regions where the sorghum map is syntenic with that of maize;

- the study on sugar cane showed little recombination within known sugar cane linkage groups; hence it is quite unlikely that two regions on a single sugar cane chromosome could be independent;

- the distributions of sorghum and sugar cane linkage groups were in close agreement.

Large chromosome rearrangements therefore probably played a significant role in the genomic evolution of the three species considered and sugar cane seems more closely related to sorghum than to maize in this respect. 
Table 1 Description of tentative synteny clusters between maize, sugar cane and sorghum (designated as the corresponding sugar cane linkage groups). For each locus, the maize chromosomal assignment is given, as well as its sugar cane (D'Hont et al., 1994, except for probes UMC109, UMC113 and BNL5.04, this study) and/or sorghum (W for map of Whitkus et al., 1992, M for map of Melake Berhan et al., 1993) linkage group assignments. Within each cluster, locus order is given according to the maize map (from top to bottom of each chromosome in Fig. 1)

\begin{tabular}{|c|c|c|c|c|c|c|c|c|c|}
\hline \multicolumn{2}{|c|}{$\begin{array}{l}\text { Maize probes and } \\
\text { Isozymes ab }\end{array}$} & \multirow{2}{*}{$\begin{array}{c}\text { Sugarcane } \\
\text { linkage } \\
\text { groups }^{c}\end{array}$} & \multicolumn{2}{|c|}{$\begin{array}{l}\text { Sorghum linkage } \\
\text { groups }\end{array}$} & \multicolumn{2}{|c|}{$\begin{array}{l}\text { Maize probes and } \\
\text { Isozymes ab }\end{array}$} & \multirow{2}{*}{$\begin{array}{c}\text { Sugarcane } \\
\text { linkage } \\
\text { groups }\end{array}$} & \multicolumn{2}{|c|}{$\begin{array}{l}\text { Sorghum linkage } \\
\text { groups }^{c d}\end{array}$} \\
\hline name & chr. & & W & $\overline{\mathbf{M}}$ & name & chr. & & $\vec{W}$ & $\overline{\mathbf{M}}$ \\
\hline \multicolumn{5}{|c|}{ SYNT. CLUSTER A } & \multicolumn{5}{|c|}{ SYNT. CLUSTER D (continued) } \\
\hline BNL05.62 & 1 & & C & & NPI283 & 7 & & & B \\
\hline UMC164 & 1 & A & & & BNL08.32 & 7 & & & B \\
\hline UMC157 & 1 & A & & & UMC125B & 7 & & & B \\
\hline UMC115 & 1 & A & & & BNL07.61 & 7 & & & $\overline{\mathbf{B}}$ \\
\hline UMC29 & 1 & & $\mathrm{C} / \mathrm{D}$ & & BNL14.07 & 7 & & D & $\mathbf{B}$ \\
\hline UMCO76 & 1 & & C & $(E)^{* *}$ & Tpil(iso) & 7 & & D & \\
\hline BNL12.06 & 1 & $\mathbf{A} / \mathbf{B}$ & & & BNL08.37 & 7 & & & B \\
\hline BNL05.02 & 5 & & C & & BNL08.39 & 7 & D & & \\
\hline PIO200904 & 6 & & $\mathrm{C} / \mathrm{I}^{* *}$ & & UMC168 & 7 & & D & \\
\hline BNL09.05 & 9 & A & C & & BNL16.06 & 7 & D & D & \\
\hline BNL14.28 & 9 & A & C & & $\overline{\text { BNL08.44 }}$ & 7 & D & & $(0)^{* *}$ \\
\hline & & & & & PIO200728 & 7 & & D & \\
\hline SYNT. CLU & IER B & & & & & & & & \\
\hline BNL10.38 & 1 & & & D & $\begin{array}{l}\text { SYNT. CLUS } \\
\text { UMCO32 }\end{array}$ & $\underset{3}{\text { ER F }}$ & & & \\
\hline BNL12.06 & 1 & $\mathbf{B} / \mathbf{A}$ & & & UMC032 & 3 & & $\mathbf{F}$ & $(M)^{* *}$ \\
\hline UMCO53 & 2 & & & D & UMC121 & 3 & & $\mathbf{F}$ & \\
\hline UMCO06 & 2 & B & $\mathbf{E}$ & D & BNL13.05B & 3 & & $\mathbf{F}$ & \\
\hline$\overline{\mathrm{UMC}} \mathrm{C4} \mathrm{B}$ & 2 & B & & D & UMC097 & 3 & & (D) & A \\
\hline BNL08.04 & 2 & & & D & NPI446 & 3 & & $\mathbf{F}$ & \\
\hline UMC061 & 2 & & $\mathbf{E}$ & & BNL05.37 & 3 & & & A \\
\hline BNL12.09 & 2 & B & & & UMC060 & 3 & & & A \\
\hline UMC135 & 2 & & $\mathbf{E}$ & (B) & BNL15.20 & 3 & & $(\mathrm{M})^{* *}$ & A \\
\hline UMC177 & 10 & & $\overline{\mathbf{E}}$ & & UMC003B & 3 & & & A \\
\hline UMC44A & 10 & B & & D & BNL03.18 & 3 & $\mathbf{F}$ & & A \\
\hline$\overline{\text { BNL10.13 }}$ & 10 & & $\mathbf{E}$ & (G) & UMCO39 & 3 & $\mathbf{F}$ & & \\
\hline BNL07.49 & 10 & B & $\overline{\mathbf{E}}$ & & BNL1.297 & 3 & $\mathbf{F}$ & & \\
\hline$\overline{\text { PIO200568 }}$ & 10 & & $\mathbf{E}$ & & $\mathrm{UMCO}^{7}$ & 3 & & & A \\
\hline NPI350 & 10 & & $\overline{\mathbf{E}}$ & & UMCO10 & 3 & & & A \\
\hline & & & & & UMC199 & 3 & & & A \\
\hline SYNT. CLU & TER C & & & & PIO200726 & 3 & & $\mathbf{F}$ & A \\
\hline UMC128 & 1 & & B & & BNL06.22 & 5 & $\mathbf{F}$ & & \\
\hline $\operatorname{Mmm}$ (iso) & 1 & & B & & NPI1 14 & 8 & & $\mathbf{F}$ & \\
\hline BNL15.18 & 1 & & & $\mathbf{K}$ & BNL13.05 A & 8 & & $\mathbf{F}$ & \\
\hline UMC107A & 1 & C & & $\mathbf{K}$ & UMC124 & 8 & & $\mathbf{F}$ & \\
\hline UMC106A & 1 & & $\mathrm{~B} / \mathrm{D}$ & & UMCO93 & 8 & $\mathbf{F}$ & $\mathbf{F}$ & A \\
\hline ADH 1 & 1 & C & & & UMCO30 & 8 & & & A \\
\hline BNL07.25 & 1 & & & $\mathrm{~K}$ & UMC1 17 & 8 & & $(M)^{* *}$ & A \\
\hline UMCO84 & 1 & C & & $\mathbf{K}$ & UMC107 & 8 & $\mathbf{F}$ & $(I)^{* *}$ & \\
\hline PIO200557 & 1 & & & $\mathbf{K}$ & UMC003A & 8 & & & A \\
\hline BNL06.25 & 5 & & B & $\mathbf{K}$ & UMC109 & 9 & (H) & (J) & A \\
\hline UMC147 & 5 & C & $\overline{\mathbf{B}}$ & & UMCl14 & 9 & & & $\mathrm{~A} / \mathrm{C}$ \\
\hline UMC107B & 5 & C & & $\mathbf{K}$ & & & & & \\
\hline UMC106B & 5 & & $\mathrm{~B} / \mathrm{D}$ & & SYNT. CLU & IER G & & & \\
\hline UMCO27 & 5 & & B & & PIO200597 & 4 & & $\mathbf{H}$ & \\
\hline UMC166 & 5 & & B & & UMC127 & 4 & & $\mathbf{H}$ & \\
\hline & & & & & UMC156 & 4 & & $\mathbf{H}$ & $\mathbf{G}$ \\
\hline SYNT. CLU & TER D & & & & BNL05.71 & 5 & & $\mathbf{H}$ & $\mathbf{G}$ \\
\hline UMC29 & 1 & & $D / C$ & & UMC054 & 5 & $\mathbf{G}$ & & \\
\hline UMC129 & 1 & & & B & UMC108 & 5 & $\mathbf{G}$ & $\mathbf{H}$ & \\
\hline UMC106A & 1 & & $\mathrm{D} / \mathrm{B}$ & & $\overline{\text { BNL05.24 }}$ & 5 & & $\mathbf{H}$ & \\
\hline Tpi2(iso) & 2 & & D & & UMC104 & 5 & $\mathbf{G}$ & & $\mathbf{G}$ \\
\hline UMCO55 & 2 & & D & B & BNL10.13 & 10 & & (E) & $\mathbf{G}$ \\
\hline UMCl35 & 2 & & (E) & B & & & & & \\
\hline UMC139 & 2 & & D & B & SYNT. CLU & TER H & & & \\
\hline UMC125A & 2 & & & B & PIO060012 & 5 & & $\mathbf{J}$ & \\
\hline UMCO22 & 2 & & & B & Enp 1(iso) & 6 & & J & \\
\hline UMC088 & 2 & & D & B & PIO060007 & 6 & & J & \\
\hline UMCOO4 & 2 & D & & B & UMCO65 & 6 & & J & C \\
\hline$\overline{\mathrm{UMC} 122}$ & 2 & & & B & UMCO21 & 6 & $\mathbf{H}$ & $\mathbf{J}$ & \\
\hline UMC137 & 2 & D & & & UMC109* & 9 & $\mathbf{H}$ & $\mathbf{J}$ & (A) \\
\hline UMC097 & 3 & & D & (A) & PIO10005 & 9 & & & $\mathrm{C}$ \\
\hline UMC106B & 5 & & $\mathrm{D} / \mathrm{B}$ & & $\mathrm{UMCl13}^{*}$ & 9 & $\mathbf{H}$ & $\mathbf{J}$ & \\
\hline NPI400 & 7 & & D & & $\mathrm{Cl}$ & 9 & & & C \\
\hline BNL15.40 & 7 & & D & & shl & 9 & & & C \\
\hline UMC136 & 7 & & D & & UMC081 & 9 & $\mathbf{H}$ & & \\
\hline NPI1 12 & 7 & & & B & BNLO5.10 & 9 & & $\mathbf{J}$ & \\
\hline UMC1 16 & 7 & & & B & $w \times 1$ & 9 & & & C \\
\hline BNL15.21 & 7 & D & D & B & UMC114 & 9 & & & C/A \\
\hline UMC149 & 7 & & D & B & BNL5.04* & 9 & $\mathbf{H}$ & & C \\
\hline BNL04.24 & 7 & D & & B & BNL7.13 & 9 & & & $C$ \\
\hline
\end{tabular}




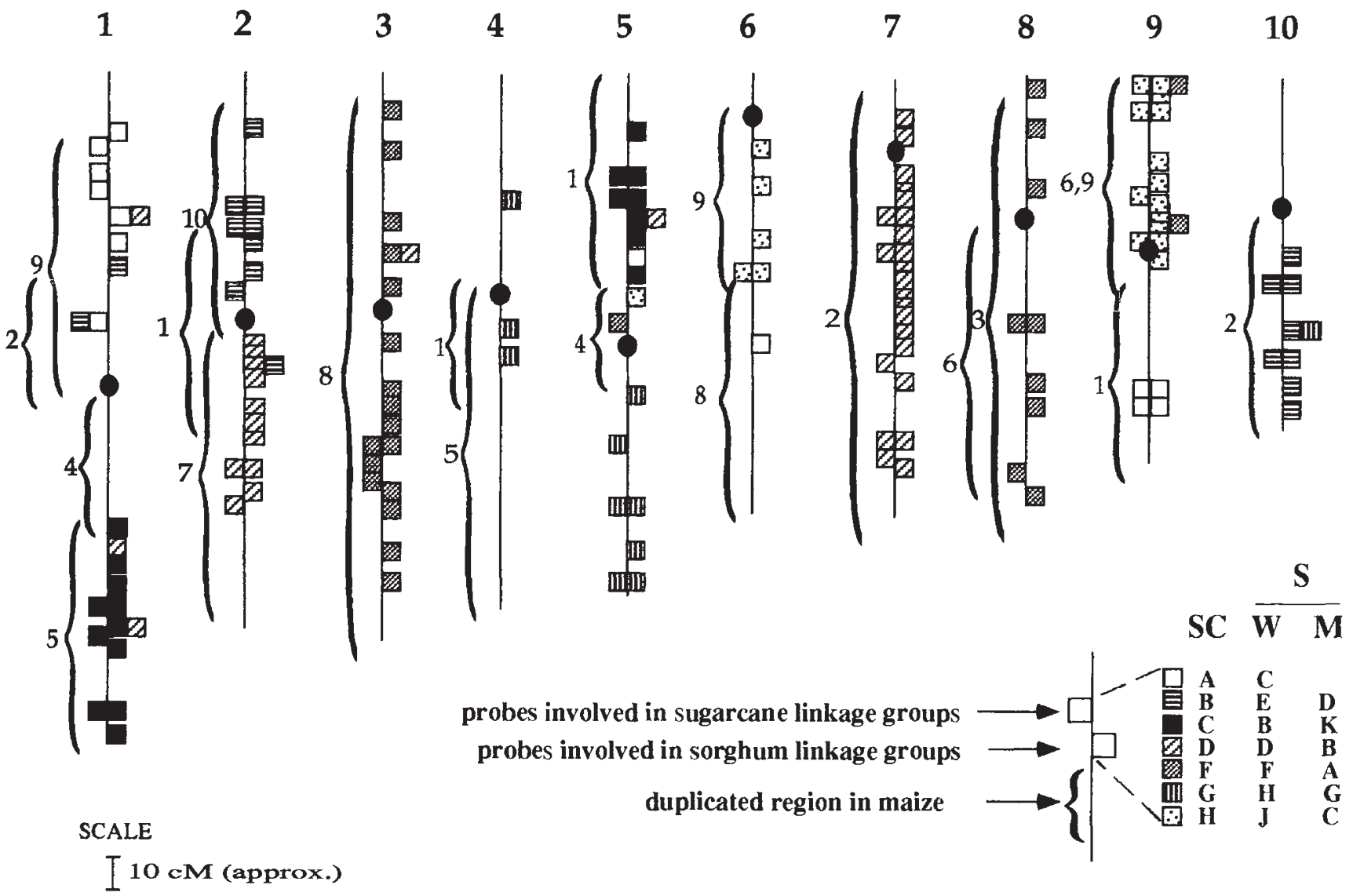

Fig. 2 Location on the maize genetic map (from Coe et al., 1988; Burr and Burr, 1991; Burr, pers. comm.; Gardiner et al., 1993) of probes involved in the synteny clusters defined in Table 1. Probes are represented by squares or horizontal rectangles whose background is indicative of the synteny cluster. Probes with two backgrounds (rectangles) belong to two clusters. Involvement in a sugar cane linkage group is indicated on the left side of the chromosome, involvement in a sorghum linkage group on the right. Correspondences between backgrounds and clusters are given at the bottom of the figure (SC for sugar cane and synteny cluster, $\mathrm{S}$ for sorghum, W for Whitkus et al., 1992, M for Melake Berhan et al., 1993). Duplicated regions within the maize genome are indicated in brackets (Dowty and Helentjaris, 1992). Note that the centromere locations are approximate.

\section{Colinearity within two synteny clusters}

Sugar cane map A total number of 53 SDRFs was generated by the 11 probes studied, 38 by the seven probes mapping maize chromosome arms $7 \mathrm{~L}$ and $2 \mathrm{~L}$, and 15 by the four probes mapping the short arm of chromosome 9. These two data sets represent sugar cane linkage groups $\mathrm{D}$ and $\mathrm{H}$, and by extension SCs D and $\mathrm{H}$.

Synteny cluster D. Only four markers out of 38 were not involved in a cosegregation group. The 34 others were scattered into nine groups (Fig. 3) of two to six markers each, varying in length from 0 to $22 \mathrm{cM}$. The distances between two given adjacent loci varied from one group to another but never exceeded $11 \mathrm{cM}$. In some cases (groups D4, D6, D7 and D9) the marker order was not clear (hatched boxes in Fig. 3), with the most likely order being less than ten times more likely than the next. Nevertheless, there was no inconsistency in marker order between groups. The composite map indicated the relative order of all loci but two, BNL.8.39 and UMC137.

Synteny cluster H. Eight markers out of 15 were linked, making three cosegregation groups of three, three and two markers, respectively. Gene orders were consistent in the first two groups. On the composite map, the position of BNL5.04 could not be determined since this probe was only involved in one cosegregation group of two markers.

\section{Comparison with maize and sorghum}

Synteny cluster D. The five probes mapping maize chromosome $7 \mathrm{~L}$ were arranged in the same order in maize and sugar cane (Fig. 4). The position of UCM4 
Fig. 3 Constitutive cosegregation groups for linkage groups $\mathrm{D}$ and $\mathrm{H}$ of sugar cane, revealed from 81 individuals of the selfed progeny of variety R570. For composite map see text.

\section{Linkage group D}

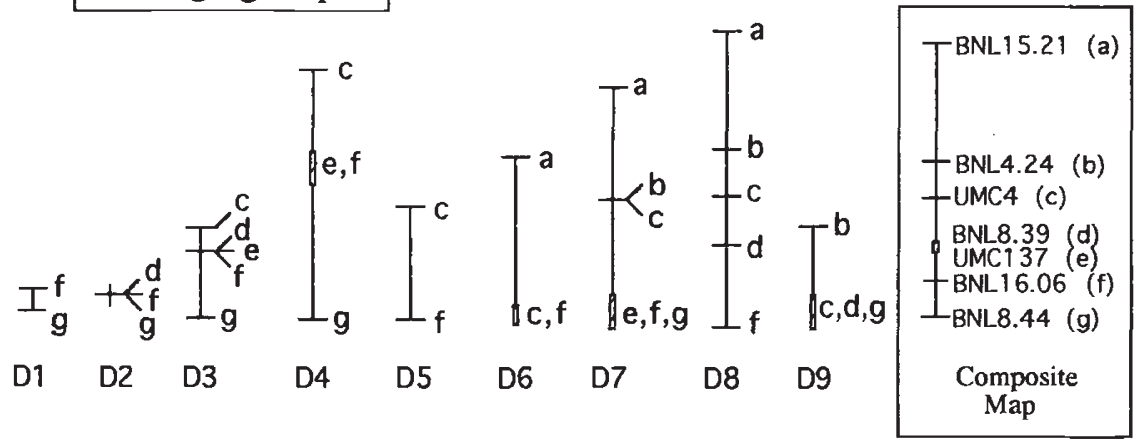

\section{Linkage group $\mathrm{H}$}

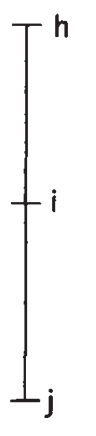

$\mathrm{H1}$
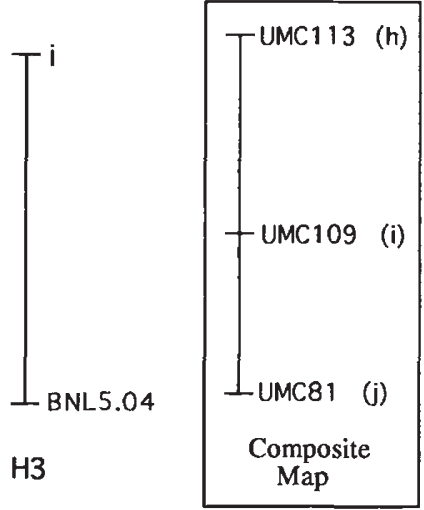

and UMC137 could not be compared since these two probes are not duplicated in maize (or the duplicated loci have not yet been mapped) and only map chromosome 2L. Comparison of the two sorghum maps revealed a common order of probes BNL15.21, BNL4.24 and BNL16.06 in sorghum and sugar cane. Probe UMC4 cosegregated with BNL4.24 in sorghum, which is in line with the very close position of the two probes in sugar cane. The two extreme markers BNL15.21 and BNL16.06 are separated by $73 \mathrm{cM}$ in maize, $54 \mathrm{cM}$ in sorghum (map of Whitkus et al., 1992) and $20 \mathrm{cM}$ in sugar cane.

Synteny cluster H. The position of UMC109 was found to be inverted in maize as compared to sugar cane and sorghum. The location of UMC81, BNL5.10 and UMC114 in the maize map suggested that the locus order is probably the same in sugar cane and sorghum. It would be of no interest to compare distances between probes UMC109 and UMC81 since there is probably an inversion breaking point between these probes in maize as compared to sorghum and sugar cane. The distance between UMC109 and UMC113 was around $15 \mathrm{cM}$ for the three species.

\section{Discussion}

Synteny is a major feature demonstrated by molecular mapping of plant genomes (Moore et al., 1993; Bennetzen \& Freeling, 1993). It was first described in the Solanaceae (Bonierbale et al., 1988) and the Triticeae (Sharp et al., 1988), and has helped to point out bridges between more distantly related species such as maize, rice and wheat (Ahn \& Tanksley, 1993; Ahn et al., 1993). There have been significant advances in the Andropogoneae tribe with mapping comparisons between maize and sorghum. The former has become a model crop in many respects and the latter, thanks to its smaller genome size, is now receiving much attention in the application of molecular tools to breeding. Our comparative mapping results now add the related genus Saccharum.

Saccharum may include several polyploid series with different base numbers, given the distribution of chromosome numbers in spontaneous forms of different recognized species in this genus (Sreenivasan et al., 1987). Sorting out genome relationships within this genus could thus illustrate genomic evolution in a rela- 


\section{SYNTENY CLUSTER D}

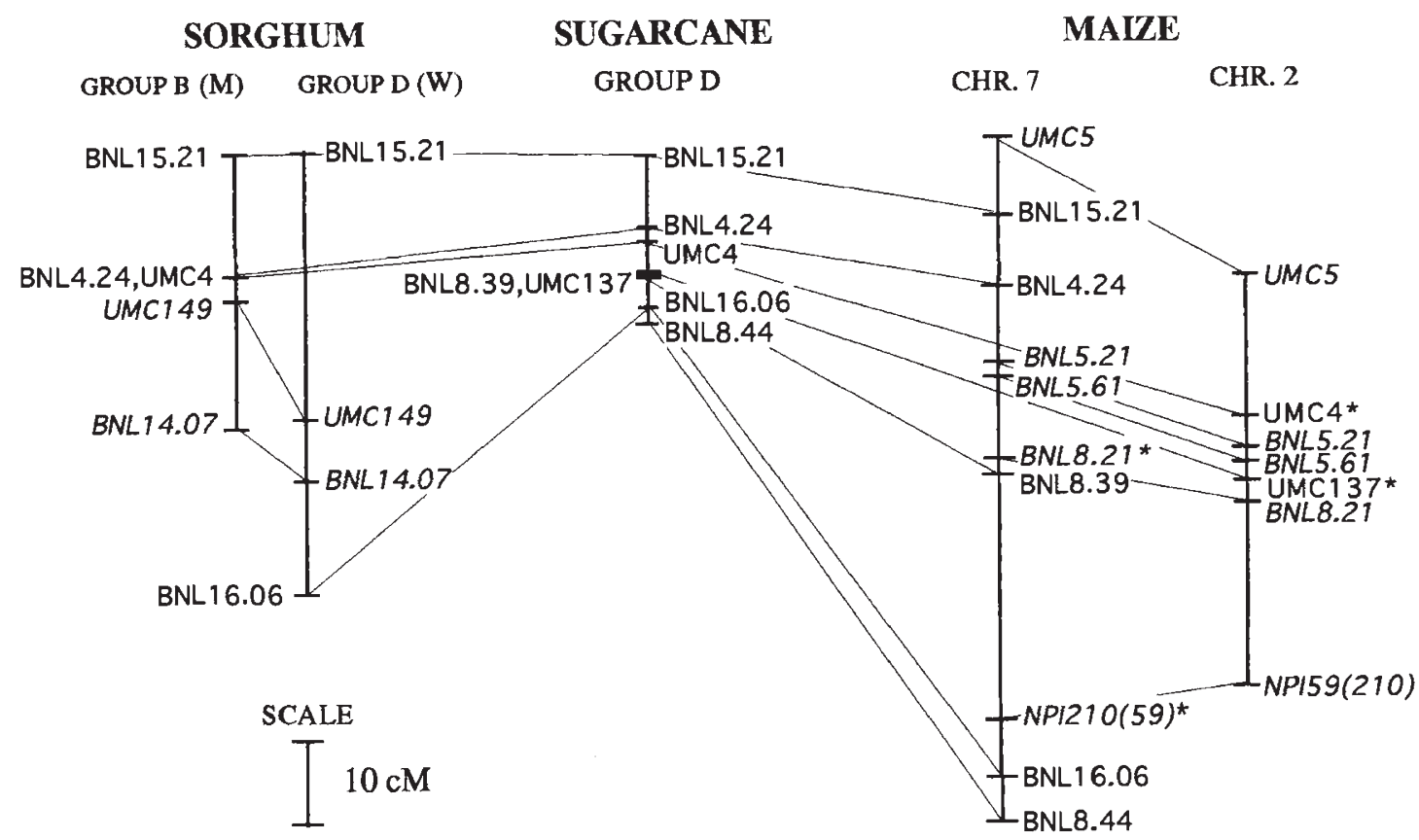

\section{SYNTENY CLUSTER H}

$\begin{array}{ccc}\text { SORGHUM } & \text { SUGARCANE } & \text { MAIZE } \\ \text { GROUP J (W) } & \text { GROUP H } & \text { CHR. } 9\end{array}$

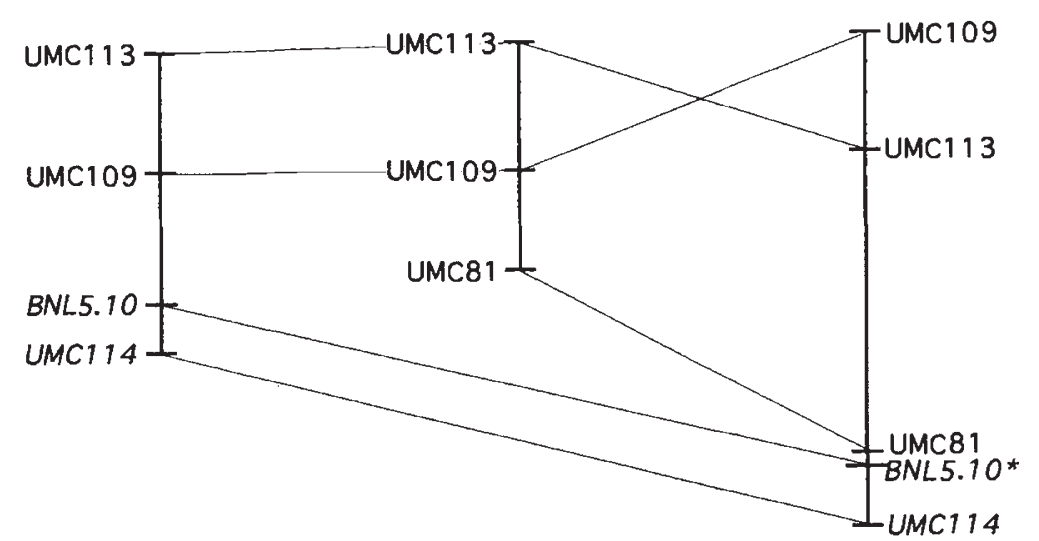

Fig. 4 Comparison of loci order and recombination rates among sugar cane (composite map, Fig. 2), maize and sorghum (Melake Berhan et al., 1993-group B; Whitkus et al., 1992-groups D and J) in synteny clusters D and H. Loci that are not involved in sugar cane linkage groups appear in italics. Two references are given for each maize chromosomal segment (CHR. 2, Helentjaris, pers. comm., * Gardiner et al., 1993; CHR. 7, Burr and Burr, 1991, ${ }^{*}$ Helentjaris, pers. comm.; CHR. 9, Gardiner et al. $1993,{ }^{*}$ Burr and Burr, 1991). The first one gives the source of the base map, the second gives the source through which loci with an * were added.

tively narrow group of the Andropogoneae. Although differences in basic chromosome numbers within a genus can be due to events such as centric fusion, fissions or whole chromosome duplications (Quiros et al., 1987; Saideswara et al., 1989; Raina, 1990), finer genome restructuring cannot be excluded. In the present work, an overall comparison of maize, sorghum and sugar cane genomes was undertaken 
using linkage groups established in the $S$. spontaneum genome to represent sugar cane (D'Hont et al., 1994). A more accurate comparison within two synteny clusters was performed without considering the specific origins of SDRFs (inherited from S. officinarum or $S$. spontaneum). Although in our previous study, we did not find any differences in gene composition between cosegregation groups inherited from $S$. spontaneum and $S$. officinarum, the possible differences between the two basic genomes have to be kept in mind.

The comparison of sugar cane with maize and sorghum involves a wider evolutionary scale. The first comparisons of linkage groups depicted in sugar cane, sorghum and maize suggest that large chromosome rearrangements, i.e. translocations, centric fusions or fissions, may have played a significant evolutionary role. A detailed comparison of genome fractions corresponding to synteny cluster D suggests conservation of the physical structure of this portion of the chromosome in all three species.

The case of probes UMC4 and UMC137 illustrates the probable rapid molecular evolution within the maize genome subsequent to duplication. Although these probes were found to fall within a cluster of loci on the maize $2 \mathrm{~L}$ chromosome arm which is known to be duplicated on chromsome $7 \mathrm{~L}$, they do not seem to map the latter portion, probably due to loss of homology. This also applies for probes BNL4.24, BNL8.39, BNL8.44, BNL15.21 and BNL16.06 which do not map maize chromosome arm 2L. The DNA sequences corresponding to sugar cane and sorghum linkage groups could therefore be closer to the common ancestral sequence than those found in maize.

Synteny cluster $\mathrm{H}$ showed an inversion on maize chromosome $9 \mathrm{~L}$ as compared to the sorghum and sugar cane counterparts. This has already been discussed by Melake Berhan et al. (1993), who noted that this inversion differentiates maize from the very closely related teosinte, and thus was probably a quite recent event.

The present study is informative for the analysis of genome evolution in the diversification of grasses. Within the Andropogoneae, there appears to be a high degree of conservation in gene composition between the sugar cane and sorghum linkage groups on the one hand and duplicated portions of maize chromosomes on the other. Colinearity was also shown in the two linkage groups investigated for this purpose. These genome structure similarities between the three related species provide a first insight into the organization of the common ancestral genome. Further comparative analysis of chromosomal organization among the Andropogoneae and other grasses could delineate the genome rearrangements that occurred during evolution of the major current crop species. Comparative genome analyses in relation to time should take possible 'accelerations' into account, as seem to have occurred in maize.

\section{Acknowledgements}

We thank Dr B. Burr and Dr T. Helentjaris, who kindly provided unpublished information on maize mapping.

\section{References}

AHN, S. AND TANKSLEY, S. D. 1993. Comparative linkage maps of the rice and maize genomes. Proc. Natl. Acad. Sci. U.S.A., 93, 7980-7984.

AHN, S., ANDERSON, J. A., SORRELLS, M. E. AND TANKSLEY, S. D. 1993. Homeologous relationships of rice, wheat and maize chromosomes. Mol. Gen. Genet., 241, 483-490.

AL-JANABI, S. M., HONEYCUTT, R. J., McCLELLAND, M. AND SOBRAL, B W. S. 1993. A genetic linkage map of Saccharum spontaneum L. 'SES208'. Genetics, 134, 1249-1260.

BENNETZEN, J. L. AND FREELING, M. 1993. Grasses as a single system: genome composition, collinearity and compatibility. Trends Genet., 9, 259-261.

BINELLI, G., GIANFRANCESCHI, L., PE, M. E., TARAMINo, G., BUSSO, C., STENHOUSE, J. AND OTTAVIANO, E. 1992. Similarity of maize and sorghum genomes as revealed by maize RFLP probes. Theor. Appl. Genet., 84, 10-16.

BONIERBALE, M. W., PlaisTED, R. L. AND TANKSLEY, S. D. 1988. RFLP maps based on a common set of clones reveal modes of chromosomal evolution in potato and tomato. Genetics, 120, 1095-1103.

BURR, B. AND BURR, A. 1991. Recombinant inbreds for molecular mapping in maize. Trends Genet., 7, 55-60.

COE, E. H., Jr, NEUfFER, M. G. AND HOISINGTON, D. A. 1988. The genetics of corn. In: Sprague, G. F. and Dudley, J. W. (eds) Corn and Corn Improvement, 3rd edn, pp. 81-257. American Society of Agronomy, Madison, WI.

DA SILVA, A. G., SORRELLS, M. E., BURNQUIST, W. L. AND TANKSLEY, S. D. 1993. RFLP linkage map and genome analysis of Saccharum spontaneum. Genome, 36, 782-791.

D'HONT, A., LU, Y.-H., GONZÁLEZ DE LEEON, D., GRIVET, L., FELDMANN, P., LANAUd, C. AND GlasZMANN, J. C. 1994. A molecular approach to unraveling the genetics of sugarcane, a complex polyploid of the Andropogoneae tribe. Genome, 37, 222-230.

DOWTY, J. AND HELENTJARIS, T. 1992. Duplicated RFLP loci are abundant in the genome. Maize Genet. Coop. Newsl., 66, 106.

EKSOMTRAMAGE, T., PAULET, F., NOYER, J. L., FELDMANN, P. AND GLASZMANN, J. C. 1992. Utility of isozymes in sugarcane breeding. Sugar Cane, 3, 14-21. 
GARDINER, J. R., COE, E. H., MELIA-HANCOCK, S., HOISINGTON, D. A. AND CHAO, s. 1993. Development of a core RFLP map in maize using an immortalized $F_{2}$ population. Genetics, 134, 917-930.

GlaszmanN, J. C., FAUTRET, A., NOYer, J. L., FEldMANN, P. AND LANAUD, C. 1989. Biochemical genetic markers in sugarcane. Theor. Appl. Genet., 78, 537-543.

HELENTJARIS, T., WEBER, D. AND WRIGHT, S. 1988. Identification of the genomic locations of duplicate nucleotide sequences in maize by analysis of restriction fragment length polymorphisms. Genetics, 118, 353-363.

HOISINGTON, D. 1992. Laboratory protocols. CIMMYT Applied Molecular Genetics Laboratory. Mexico, D.F. CIMMYT.

HULBERT, S. H., RICHTER, T. E., AXTELL, J. D. AND BENNETZEN, J. L. 1990. Genetic mapping and characterization of sorghum and related crops by means of maize DNA probes. Proc. Natl. Acad. Sci., U.S.A., 87, 4251-4255.

LANDER, E. S., GREEN, P., AbRAhAMSON, J., BARLOW, A., DALY, M. J., LINCOLN, S. E. AND NEWBERG, L. 1987. Mapmaker: an interactive computer package for constructing primary genetic linkage maps of experimental and natural populations. Genomics, 1, 174-181.

LU, Y.-H., D'HONT, A., WALKER, D. I. T., RAO, P. S., FELDMANN, P. AND GLASZMANN, J. C. Relationships among ancestral species of sugarcane revealed with RFLP using single copy mazie nuclear probes. Euphytica, in press.

MELAKE BERHAN, A., HULBERT, S. H., BUTLER, L. G. AND BENNETZEN, J. L. 1993. Structure and evolution of the genomes of Sorghum bicolor and Zea mays. Theor. Appl. Genet., 86, 598-604.

MOORE, G., GALE, M. D., KURATA, N. AND FLAVELL, R. B. 1993.
Molecular analysis of small grain cereal genomes: current status and prospects. Bio/Technology, 11, 584-589.

QUIROS, C. F., OCHOA, O., KIANIAN, S. F. AND DOUCHES, D. 1987. Analysis of the Brassica oleracea chromosome addition lines: characterisation by isozymes and rDNA genes. Theor. Appl. Genet., 74, 758-766.

RAINA, S. N. 1990. Genome organisation and evolution in the genus Vicia. In: Kawano, S. (ed.) Biological Approaches and Evolutionary Trends in Plants, pp. 183-201. Academic Press, London.

SAGHAI MAROOF, M. A., SOLIMAN, R. A., JORGENSEN, R. A. AND ALLARD, A. W. 1984. Ribosomal DNA spacer-length polymorphisms in barley: Mendelian inheritance, chromosomal location and population dynamics, Proc. Natl. Acad. Sci. U.S.A., 81, 8014-8018.

SAIDESWARA RAO, Y., APPA RAO, S. AND MELAK MENGESHA, H. 1989. New evidence on the phylogeny of basic chromosome number in Pennisetum. Curr. Sci., 58, 869-871.

SHARP, P. J., KREIS, M., SHEWRY, P. R. AND GALE, M. D. 1988. Location of beta-amylase sequences in wheat and its relatives. Theor. Appl. Genet., 75, 286-290.

SREENIVASAN, T. v., AHLOOWALIA, B. S. AND HEINZ, D. J. 1987. Cytogenetics. In: Heinz, D. J., (ed.) Sugarcane Improvement Through Breeding, pp. 211-253. Elsevier Press, Amsterdam.

WhitkUS, R., DOEBLEY, J. AND LEE, M. 1992. Comparative genome mapping of sorghum and maize. Genetics, 132, 1119-1130.

WU, K. K., BURNQUIST, W., SORRELLS, M. E., TEW, T. L., MOORE, P. H. AND TANKSLEY, S. D. 1992. The detection and estimation of linkage in polyploids using single-dose restriction fragments. Theor. Appl. Genet., 83, 294-300. 